\title{
Inhibition of AChE by malathion and some structurally similar compounds
}

\section{Danijela Z. Krstić, Mirjana Čolović, Mojca Bavcon kralj, Mladen Franko, Katarina Krinulović, Polonca Trebše \& VESNA VASIĆ}

To cite this article: Danijela Z. Krstić, Mirjana Čolović, Mojca Bavcon kralj, Mladen Franko, Katarina Krinulović, Polonca Trebše \& VESNA VASIĆ (2008) Inhibition of AChE by malathion and some structurally similar compounds, Journal of Enzyme Inhibition and Medicinal Chemistry, 23:4, 562-573, DOI: $10.1080 / 14756360701632031$

To link to this article: https://doi.org/10.1080/14756360701632031

\section{册 Published online: 04 Oct 2008.}

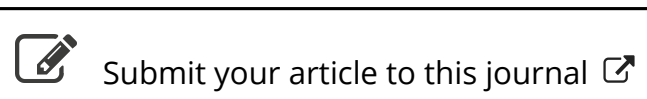

Lll Article views: 567

Q View related articles $₫$

4 Citing articles: 14 View citing articles $\asymp$ 


\title{
Inhibition of AChE by malathion and some structurally similar compounds
}

\author{
DANIJELA Z. KRSTIĆ ${ }^{1}$, MIRJANA ČOLOVIĆ ${ }^{2}$, MOJCA BAVCON KRALJ ${ }^{3}$, MLADEN \\ FRANKO $^{3}$, KATARINA KRINULOVIĆ ${ }^{2}$, POLONCA TREBŠE ${ }^{3}$, \& VESNA VASIĆ $^{2}$ \\ ${ }^{1}$ Institute of Chemistry; School of Medicine, University of Belgrade, Belgrade, Serbia, ${ }^{2}$ Vinca Institute of Nuclear Sciences, \\ Belgrade, Serbia, and ${ }^{3}$ Laboratory for Environmental Research, University of Nova Gorica, Nova Gorica, Slovenia
}

(Received 30 April 2007; in final form 26 fuly 2007)

\begin{abstract}
Inhibition of bovine erythrocyte acetylcholinesterase (free and immobilized on controlled pore glass) by separate and simultaneous exposure to malathion and malathion transformation products which are generally formed during storage or through natural or photochemical degradation was investigated. Increasing concentrations of malathion, its oxidation product malaoxon, and its isomerisation product isomalathion inhibited free and immobilized AChE in a concentration-dependent manner. $\mathrm{K}_{\mathrm{I}}$, the dissociation constant for the initial reversible enzyme inhibitor-complex, and $\mathrm{k}_{3}$, the first order rate constant for the conversion of the reversible complex into the irreversibly inhibited enzyme, were determined from the progressive development of inhibition produced by reaction of native AChE with malathion, malaoxon and isomalathion. $\mathrm{K}_{\mathrm{I}}$ values of $1.3 \times 10^{-4} \mathrm{M}^{-1}, 5.6 \times 10^{-6} \mathrm{M}^{-1}$ and $7.2 \times 10^{-6} \mathrm{M}^{-1}$ were obtained for malathion, malaoxon and isomalathion, respectively. The $\mathrm{IC}_{50}$ values for free/immobilized AChE, $(3.7 \pm 0.2) \times 10^{-4} \mathrm{M} /(1.6 \pm 0.1) \times 10^{-4},(2.4 \pm 0.3) \times 10^{-6} /(3.4 \pm 0.1) \times$ $10^{-6} \mathrm{M}$ and $(3.2 \pm 0.3) \times 10^{-6} \mathrm{M} /(2.7 \pm 0.2) \times 10^{-6} \mathrm{M}$, were obtained from the inhibition curves induced by malathion, malaoxon and isomalathion, respectively. However, the products formed due to photoinduced degradation, phosphorodithioic O,O,S-trimethyl ester and O,O-dimethyl thiophosphate, did not noticeably affect enzymatic activity, while diethyl maleate inhibited AChE activity at concentrations $>10 \mathrm{mM}$. Inhibition of acetylcholinesterase increased with the time of exposure to malathion and its inhibiting by-products within the interval from 0 to 5 minutes. Through simultaneous exposure of the enzyme to malaoxon and isomalathion, an additive effect was achieved for lower concentrations of the inhibitors (in the presence of malaoxon/isomalathion at concentrations $2 \times 10^{-7} \mathrm{M} / 2 \times 10^{-7} \mathrm{M}, 2 \times 10^{-7} \mathrm{M} / 3 \times 10^{-7} \mathrm{M}$ and $2 \times 10^{-7} \mathrm{M} / 4.5 \times 10^{-7} \mathrm{M}$ ), while an antagonistic effect was obtained for all higher concentrations of inhibitors. The presence of a non-inhibitory degradation product (phosphorodithioic O,O,S-trimethyl ester) did not affect the inhibition efficiencies of the malathion by-products, malaoxon and isomalathion.
\end{abstract}

Keywords: free and immobilized acetylcholinesterase, inhibition, malathion, isomalathion, malaoxon

\section{Introduction}

Organophosphorus (OP) compounds, such as malathion, chlorpyrifos, parathion, have been commonly used as insecticides for over 50 years [1]. These compounds, as well as the organophosphate nerve agents (sarin, soman, tabun and VX), specifically inhibit acetylcholinesterase (AChE, EC 3.1.1.7), the enzyme involved in the hydrolysis of the neurotransmitter acetylcholine (ACh) at cholinergic synapses in the central and peripheral nervous systems (cholinergic syndrome) [2-5].

Organophosphates are preferred in agriculture because of their relatively low persistence in the environment. However, they are indiscriminate pesticides and are highly toxic to animals and humans. In addition to acute (short-term) toxic effects based on acetylcholinesterase inhibition, which leads to

Correspondence: V. Vasic, Laboratory of Physical Chemistry, Vinča Institute of Nuclear Sciences, P.O. Box 522, 11001 Belgrade, Serbia. Tel.: + 381-11-2453-967. Fax: +381-11-2447-207. E-mail: evasic@vin.bg.ac.yu. P. Trebše, Laboratory for Environmental Research, University of Nova Gorica, Vipavska 13, P.O. Box 301, 5001-SI Nova Gorica, Slovenia. Tel.: + 38653315238 . Fax: +3865 3315296. E-mail: polonca.trebse@p-ng.si (P. Trebše). 
accumulation of acetylcholine, chronic low-level exposure to these compounds has been implicated as a causal factor in a variety of human diseases involving the nervous or immune systems [6,7]. Moreover, the toxicity of organophosphates is significantly increased by their break-down products, which may be bioactivated within an organism or through exposure to the sunlight [8-10].

When applied, OPs are usually completely removed by physico-chemical water treatment methods before getting into the potable water supply. The use of oxidation procedures or irradiation methods to remove organophosphates leads to different chemical transformations, e.g., hydrolysis, oxidation and isomerisation $[1,11]$. Surveys of pesticide trace amounts generally include the monitoring of parent OPs, but the more polar, water-soluble transformation products (oxons), which can be highly toxic, are usually not target analytes [12].

This work deals with the investigation of inhibition of bovine erythrocyte acetylcholinesterase by malathion and several of its degradation products, which are generally formed during water purification and/or several irradiation treatments: malaoxon, isomalathion, diethyl maleate, O,O-dimethyl thiophosphate and $\mathrm{O}, \mathrm{O}, \mathrm{S}$-trimethylphosphorodithioic ester [OOS(S)]. Malathion is a broad-spectrum insecticide, and it was chosen as a model compound because it has been one of the most commonly applied OPs since 1956. Approximately 15 million pounds of malathion active ingredient are used annually in the US, mostly in cotton production [13]. During the last decade, however, there have been many studies to assess human health risks associated with the use of malathion. In July 2006, the United States Environmental Protection Agency (EPA) determined that malathion-containing products are eligible for reregistration, provided that risk mitigation measures are adopted and labels are amended accordingly (EPA 738-R-06-030). Despite this, in September 2006, the Standing Committee on the Food Chain and Animal Health voted for the non-inclusion of malathion in Annex I of Directive 91/414/EEC [14]. This was done because it was not possible to conclude that malathion met the safety criteria for inclusion in Annex I to Directive $91 / 414 /$ EEC on the basis of the information available. Based upon presently available information, it is evident that there are two blocks of completely opposite opinions regarding malathion usage. However, our belief is that malathion and its degradation products are and will be present in our environment for a while.

As malathion reacts and breaks down within an organism or upon exposure to sunlight, one of the chemicals released, malaoxon, is about 100 times more toxic than its parent compound [10]. The aim of our study was to apply two model systems based on inhibition of AChE for evaluation of the inhibitory power of malathion and the products of its photochemically- or chemically-induced transformations.
The models were set up in a batch mode, where the free enzyme was exposed to selected OPs in vitro, and in a flow-injection analysis (FIA) mode, where a bioanalytical column was filled with immobilized bovine erythrocyte acetylcholinesterase.

The FIA-bioassay [15-17] was tested as a rapid biosensing system for the detection and determination of OPs and their breakdown products in water samples, whereas the in vitro model served as a reference. In addition, in a novel approach, the effect of simultaneous exposure of AChE to different synthetic combinations of malathion and its photoinduced byproducts, identified in a malathion photodegradation study [8], was investigated and evaluated.

\section{Materials and methods}

\section{Reagents}

All chemicals were of analytical grade. Acetylcholinesterase (AChE, specific activity $0.28 \mathrm{IU} / \mathrm{mg}$ ) from bovine erythrocytes, acetylthiocholine iodide (ASChI), 5,5'-dithio-bis-(2-nitrobenzoic acid) (DTNB) and controlled-pore glass (CPG 240, 80120 mesh) were purchased from Sigma Chemicals Co (Taufkirchen, Germany). The materials were used without further purification. Potassium hydrogen phosphate $\left(\mathrm{K}_{2} \mathrm{HPO}_{4} \times 3 \mathrm{H}_{2} \mathrm{O}\right)$, glutaraldehyde and 3-aminopropyl-triethoxysilan were purchased from Merck KGaA (Germany). The pesticides used were of at least $93 \%$ purity. Malathion $(97.3 \%)$ and malaoxon (93.7\%) were from Pestanal (Riedel-de Haen), whereas isomalathion was purchased from the Institute of Organic Industrial Chemistry (Poland) $(98.4 \%)$, diethyl maleate $(97 \%)$ was from Aldrich and $\mathrm{O}, \mathrm{O}$-dimethyl thiophosphate and O,O,S-trimethylphosphorodithioic ester were from Sigma Chemicals Co. In our previous work [8], malathion and malaoxon were tested with an AChE bioassay prior to irradiation, and the inhibition was expressed after irradiation. This finding enabled us to deduce that any impurities could not interact with AChE. The chemical structures of the studied compounds are presented in Figure 1. $0.05 \mathrm{M}$ phosphate buffer, $\mathrm{pH}$ 8, was used as a carrier buffer in the FIA experiments. The reactivation of immobilized enzyme was done using $4 \mathrm{mM}$ 2-hydroxyiminomethyl-1-methylpyridinium iodide (pralidoxime, 2-PAM). This reactivator was usually used to recover enzyme activity in FIA system [15-17], although new higher potency reactivators of OP-inhibited AChE have been synthesized in recent years [18-20].

\section{AChE assay}

The inhibition of free and immobilized enzyme was measured using Ellman's method [21] in the absence (control) and presence of inhibitors. The experiments 
<smiles>CCOC(=O)CC(SP(=S)(OC)OC)C(=O)OCC</smiles><smiles>CCOC(=O)CC(SP(=O)(OC)OC)C(=O)OCC</smiles><smiles>CCOC(=O)CC(SP(=O)(OC)SC)C(=O)OCC</smiles>

diethyl-maleat<smiles>CCOC(=O)/C=C\C(=O)OCC</smiles>

O,O-dimethyl thiophosphate<smiles>COP(O)(=S)OC</smiles>

O,O,S-trimethyl phosphorodithionate<smiles>COP(=S)(OC)SC</smiles>

Figure 1. Chemical structures of studied compounds.

were performed by in vitro (separate and simultaneous) exposure of $180 \mu \mathrm{g}$ free enzyme to inhibitors in a final volume of $0.650 \mathrm{~mL}$. The control tubes contained the corresponding concentration of ethanol without organophosphate. Acetylthiocholine iodide (ASChI) was applied as an enzyme substrate in combination with $5,5^{\prime}$-dithio-bis-2-nitrobenzoic acid (DTNB) as a chromogenic reagent. The product 5thio-2-nitrobenzoate, formed by the reaction of thiocholine (product of the enzymatic reaction) with DTNB, was measured at $412 \mathrm{~nm}$ (in buffer solution) using a Perkin Elmer Lambda 35 UV VIS spectrophotometer (Shelton, USA).

The rate of irreversible inhibition was measured according to the method introduced by Kitz et al. [22]. The samples for the assay were withdrawn at several time intervals within $20 \mathrm{~min}$ after the mixing of enzyme and inhibitor. The medium was the same composition as was used in the assay without acetylcholine.

The effects of the selected compounds on immobilized acetylcholinesterase activity was investigated by using a flow-injection analysis (FIA) system. The carrier buffer in this case was $0.05 \mathrm{M}$ phosphate buffer at $\mathrm{pH}$ 8.0. All experiments were performed in triplicate. Preliminary studies showed that malathion and its by-products, or their combinations, did not interfere with quantification of the yellow product, 5-thio-2-nitrobenzoate.

\section{Physicochemical characterization of the CPG surface}

$\mathrm{X}$-Ray analysis of the CPG surface, obtained using a Philips 1050 instrument recorded in a $2 \theta$ (scaning range from $10^{\circ}$ to $80^{\circ}$ ), showed a characteristic pattern of amorphous silica with no diffraction peaks.
The nitrogen adsorption isotherms at $77 \mathrm{~K}$ were measured using the gravimetric McBain method. Specific surface areas were calculated by the Brunaure-Emmett-Teller (BET) method using absorption data ranking from $P / P_{o}=0$ to 0.3. The BET surface area was $71 \mathrm{~m}^{2} \mathrm{~g}^{-1}$. Pore size was determined using the $\mathrm{BJH}$ method [23]. The pore size distribution of the sample showed that all pore diameters were in the range from $2-8 \mathrm{~nm}$. The particle size was $80-120$ mesh, and the pore size was $240 \AA$ nominal diameter.

FTIR spectra (FTIR Model 380, Thermo Nickolet Corporation, Madison, USA) showed characteristic silica vibrations on the CPG surface.

\section{Enzyme immobilization}

$0.55 \mathrm{mg}$ AChE was immobilized on $0.15 \mathrm{~g}$ activated controlled pore glass according to the procedure described earlier [15]. The glass particles were boiled in 5\% nitric acid. The activation step with 3aminopropyl-triethoxysilan was repeated three-times; afterwards, the glass beads were washed with deionised water and dried. Alkylamino glass was cross-linked with $2.5 \%$ glutaraldehyde solution in a stream of nitrogen and washed with deionised water. The enzyme was dissolved in $3 \mathrm{ml}$ cold phosphate buffer and added to the pre-treated glass in a stream of nitrogen. The mixture was then vacuum-filtered. The filtrate was collected in a small graduated cylinder in order to measure its exact volume. The volumes of the filtrates were $95-98 \%$ of those of the original AChE solution. The immobilized enzyme was washed with phosphate buffer and then with cold water to ensure the removal of any unlinked enzyme. The immobilized 
beads were stored at $4^{\circ} \mathrm{C}$ in phosphate buffer $(\mathrm{pH} 6.0)$ until use.

The protein content before and after the immobilization was measured by the Lowry method using BSA as a standard at $750 \mathrm{~nm}$ [24]. The free AChE activities in the initial AChE solution and in the filtrate were measured by Ellman's procedure [21]. The amount of the protein adsorbed on the glass $\left(\mathrm{P}_{\mathrm{g}}, \mathrm{mg} \mathrm{g}^{-1}\right)$ and the immobilization efficiency (\%) were determined from the following equations:

$$
\mathrm{P}_{\mathrm{g}}=\left(\mathrm{c}_{\mathrm{o}} \mathrm{V}_{\mathrm{o}}-\mathrm{c}_{\mathrm{f}} \mathrm{V}_{\mathrm{f}}\right) / \mathrm{w}=1 \mathrm{mg} \mathrm{g}^{-1}
$$

Immobilisation efficiency $(\%)$

$$
=\left[\left(\mathrm{E}_{\mathrm{o}} \mathrm{V}_{\mathrm{o}}-\mathrm{E}_{\mathrm{f}} \mathrm{V}_{\mathrm{f}}\right) / \mathrm{E}_{\mathrm{o}} \mathrm{V}_{\mathrm{o}}\right] \times 100=99 \%
$$

where $c_{o}$ is the protein concentration in the initial AChE solution ( $\left.\mathrm{mg} \mathrm{mL}^{-1}\right), \mathrm{E}_{\mathrm{o}}$ is its AChE activity (IU $\left.\mathrm{mL}^{-1}\right), \mathrm{V}_{\mathrm{o}}$ is its volume $(\mathrm{mL}), \mathrm{c}_{\mathrm{f}}$ is the protein concentration in the filtrate $\left(\mathrm{mg} \mathrm{mL}^{-1}\right), \mathrm{E}_{\mathrm{f}}$ is its $\mathrm{AChE}$ activity (IU mL $\left.{ }^{-1}\right), V_{f}$ is its volume $(\mathrm{mL})$ and $\mathrm{w}$ is the weight of the glass used $(\mathrm{g})$.

The degree of adsorption was calculated as:

$$
\alpha=\mathrm{P}_{\mathrm{g}} / \mathrm{P}_{\mathrm{g}, \mathrm{m}}=1
$$

where $\mathrm{P}_{\mathrm{g}, \mathrm{m}}\left(\mathrm{mg} \mathrm{g}^{-1}\right)$ is the maximal amount of protein adsorbed on the controlled pore glass used.

\section{Flow-injection analysis based on the AChE bioassay (FIA-AChE bioassay)}

The flow-injection system consisted of a HPLC pump (Dionex AMP-1), an injection valve (Waters U6K) and a bioanalytical column $(40 \times 4 \mathrm{~mm})$ filled with $0.55 \mathrm{mg}$ of beads with immobilized AChE. The carrier buffer (flow rate: $0.2 \mathrm{~mL} / \mathrm{min}$ ) was pumped through a flow-through cell $(250 \mu \mathrm{L})$. As was shown before, the specific activity of the immobilized AChE was not changed with respect to the activity of the free enzyme. The initial (control) enzyme activity $\left(a_{0}\right)$ of the immobilized enzyme in the bioanalytical column was determined by injecting a mixture of the substrate (ASChI) and a chromogenic reagent (DTNB). The absorbance at $412 \mathrm{~nm}$ was measured spectrophotometricly. After measurement of initial activity $a_{0}$, the sample containing the selected pesticide was injected. The remaining enzyme activity $\left(a_{r}\right)$ was determined by another injection of a mixture of ASChI and DTNB. After each injection of solution containing OPs, the activity of the enzyme was reactivated to its initial value by five consecutive injections of a reactivator $(4 \mathrm{mM}$ 2-hydroxyiminomethyl-1-methylpyridinium iodide, 2-PAM). All measurements were made in triplicate.

\section{Photodegradation procedure}

Photodegradation of malathion in aqueous solution was performed by applying our previously published method [9]. A freshly prepared pesticide solution containing less than $0.5 \%$ ethanol was purged with oxygen for $15 \mathrm{~min}$ in the dark before irradiation, and was then put into a quartz sample cell $(10 \times 10 \times 40 \mathrm{~mm})$ and placed in front of a xenon light (125 W Cermax Xenon parabolic lamp) at a distance of $45 \mathrm{~cm}$. Individual solution samples were irradiated for different periods of time $(3.5 \mathrm{~min}, 7 \mathrm{~min}$, $15 \mathrm{~min}, 30 \mathrm{~min}$, $60 \mathrm{~min}$ or $120 \mathrm{~min}$ ). The samples were analyzed by high performance liquid chromatography analysis (HPLC), ion chromatography (IC) and gas chromatography-mass spectrometry (GC-MS) [8,9]. The activity of $\mathrm{AChE}$ in the presence of pesticides after irradiation was as reported in the previous paper [8]. According to the results of the analysis, synthetic mixtures of the pure degradation products (commercial chemicals) were composed to investigate the effects on AChE activity of simultaneous exposure to malathion and its photoinduced by-products.

\section{Results}

The in vitro influence of malathion and its related compounds on free AChE activity

The influence on free AChE activity of malathion, its oxidation product malaoxon and its isomerisation product isomalathion, which is found in irradiated solutions, was investigated by in vitro exposure of the enzyme to the inhibitors in the concentration range from $1 \times 10^{-9}$ to $1 \times 10^{-1} \mathrm{M}$. In these experiments, the enzymatic reaction started immidiately after the inhibitor was added to the reaction mixture. In addition, the inhibitory potencies of $O, O, S$-trimethyl phosphorodithioic ester, diethylmaleate and O,O-dimethyl thiophosphate were also investigated, since these compounds are usually formed as a result of cleavage of $\mathrm{P}-\mathrm{S}$ and $\mathrm{P}-\mathrm{O}$ bonds due to the chemical conversion or photochemical treatment of the selected organophosphates.

The obtained results (Figure 2a) show that malathion, malaoxon, isomalathion and diethylmaleate inhibited $\mathrm{AChE}$ in a concentration-dependent manner, but with varying potencies. The dependence of AChE activity, expressed as a percentage of the control value (obtained without inhibitor) on inhibitor concentration fit a sigmoidal function in all cases.

According to the anticipated reaction scheme for the formation of phosphoryl enzyme [22], it is easy to derive the time-dependent equation for irreversibile enzyme inhibition:

$$
\ln \frac{\mathrm{E}}{E_{o}}=-\frac{k_{3} t}{1+K_{I} /(I)}
$$



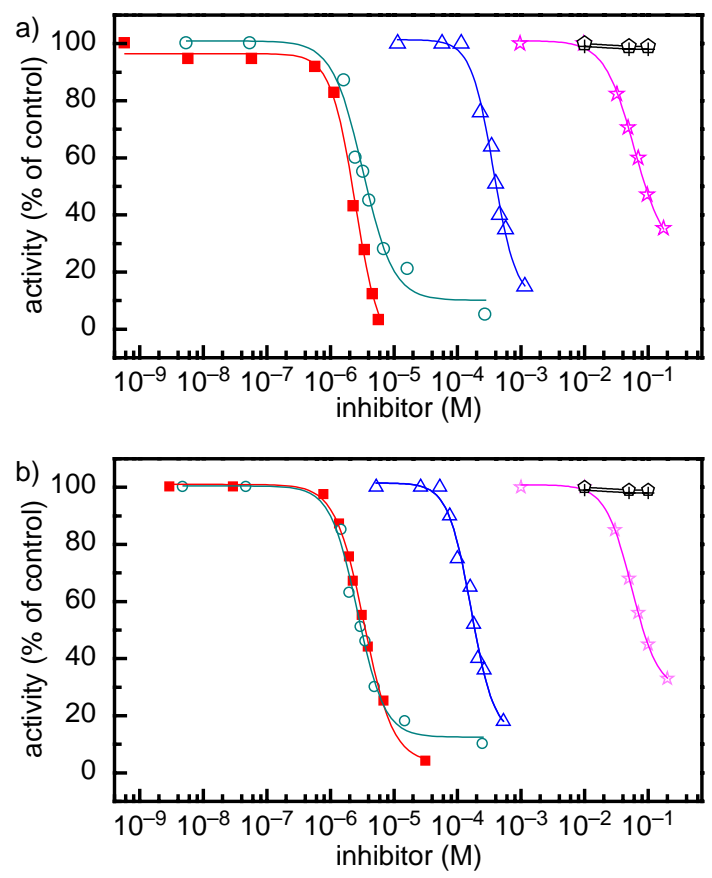

Figure 2. The concentration dependent inhibition of a) free and b) immobilized bovine erythrocytes AChE by malathion (triangle), malaoxon (square), isomalathion (circle), diethyl maleate (asterisk), $\mathrm{O}, \mathrm{O}$-dimethyl thiophosphate (pentagon) and $[\mathrm{OOS}(\mathrm{S})]$ (cross).

where $\mathrm{E} / \mathrm{E}_{\mathrm{o}}$ represents the percent of the remaining enzyme activity in relation to the initial activity, $E_{\mathrm{o}}, \mathrm{K}_{\mathrm{I}}$ is the dissociation constant for the initial reversible enzyme inhibitor complex (EI), $\mathrm{k}_{3}$ is the first order rate constant for the conversion of the reversible complex to the irreversibly inhibited enzyme and $t$ is the time interval after the mixing of the complex and the inhibitor. In our experiments, the condition $\mathrm{I} \gg \mathrm{E}_{\mathrm{o}}$ was satisfied in all cases. Consequently, the slope of Equation (4) $\left(k_{\mathrm{app}}\right)$ can be expresed in the form:

$$
\frac{1}{k_{a p p}}=\frac{1}{k_{3}}+\frac{K_{I}}{k_{3}} \cdot \frac{1}{(I)}
$$

Figure 3 represents the results obtained for malathion as an example. Irreversibile inhibition, which progressed with time in accordance with Equation 4, was obtained for malathion, malaoxon and isomalathion. The values of $k_{\text {app }}$ obtained from the slope of the dependence of $\ln \mathrm{E} / \mathrm{E}_{\mathrm{o}}$ vs. $\mathrm{t}$ where then plotted according to Equation (5) and are presented in Figure 4. Reasonably good straight lines were obtained that intercept the positive y axis, confirming that reversible complexes are formed in the concentration range studied.

The inhibition parameters $\mathrm{K}_{\mathrm{I}}$ and $\mathrm{k}_{3}$ were calculated from the slope and intercept of Equations 4 and 5 and are given in Table I, together with the halfmaximal inhibitory concentrations ( $\mathrm{IC}_{50}$ values) obtained by fitting the sigmoid inhibition curves (Figure 2) for free and immobilized enzyme.

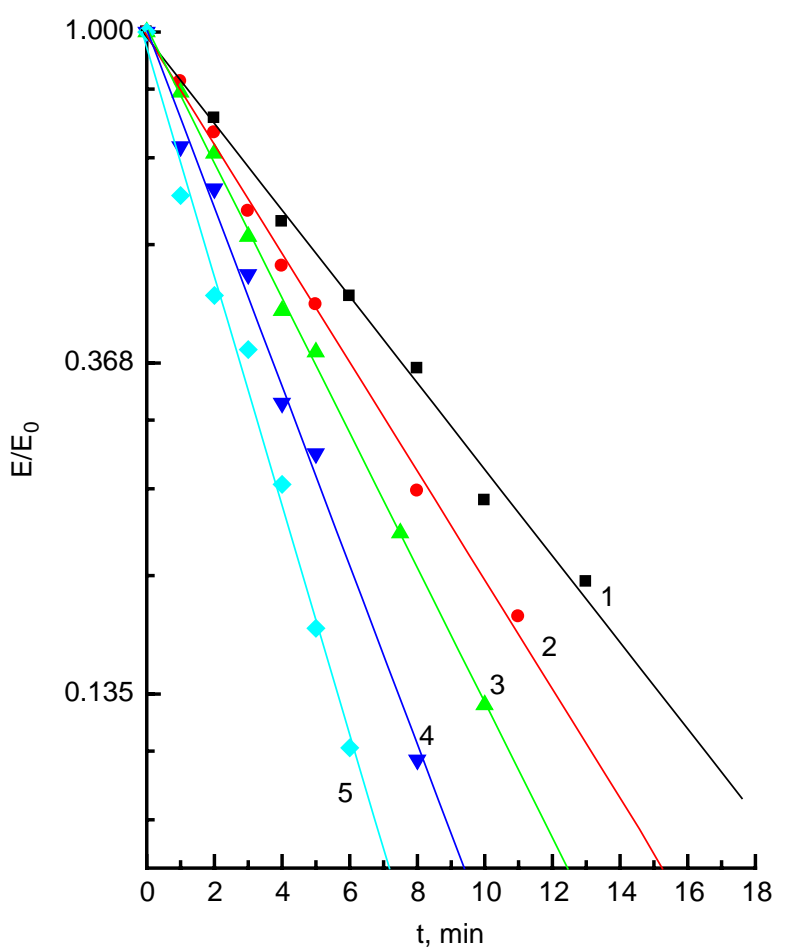

Figure 3. Progressive development of inhibition produced by reaction of acetylcholinesterase with different concentrations of malathion plotted as semilogarithmic curve in accordance with Equation 4. Malathion concentration: (1) $3 \times 10^{-5} \mathrm{M}$; (2) $4 \times 10^{-5}$ $\mathrm{M}$; (3) $5 \times 10^{-5} \mathrm{M}$; (4) $6 \times 10^{-5} \mathrm{M}$; (5) $1 \times 10^{-4} \mathrm{M}$.

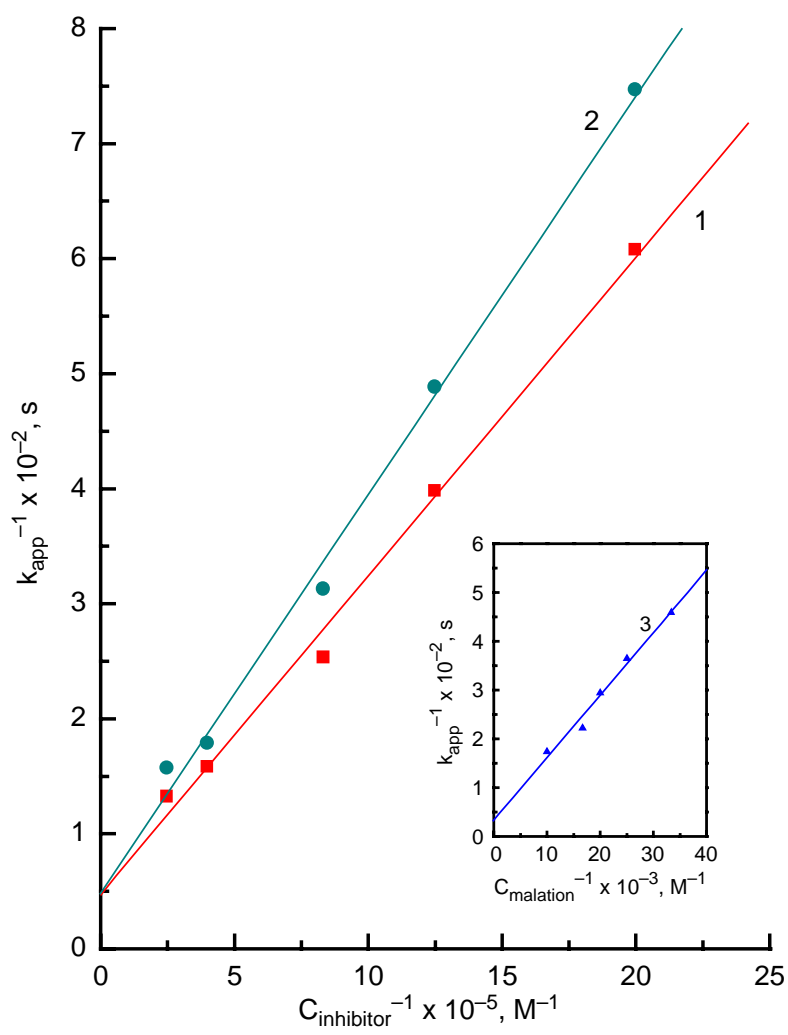

Figure 4. The dependence of $k_{\text {app }}$ upon the concentration of malaoxon (1), isomalathion (2) and malathion ((3), inset) plotted as reciprocals in accordance with Equation (5). 
Table I. The inhibition parameters and kinetic data $\left(\mathrm{IC}_{50}, \mathrm{~K}_{\mathrm{I}}\right.$ and $\left.\mathrm{k}_{3}\right)$ for irreversible inhibition of free and immobilized AChE by malathion and the products of its photochemical degradation. IC $_{50}$ values were determined by sigmoidal fit of the inhibition curves obtained under the experimental conditions described in Materials and Methods.

\begin{tabular}{lccccr}
\hline & \multicolumn{2}{c}{ Free AChE } & Immobilized AChE \\
\cline { 2 - 6 } & $\mathrm{IC}_{50},[\mathrm{M}]$ & $\mathrm{K}_{\mathrm{I}},\left[\mathrm{M}^{-1}\right]$ & $\mathrm{k}_{3}\left[\mathrm{~s}^{-1}\right]$ & $\mathrm{k}_{3} / \mathrm{K}_{\mathrm{I}}=\mathrm{k}_{3}, 1 \mathrm{~mol}^{-1} \mathrm{~s}^{-1}$ & $\mathrm{IC}_{50},[\mathrm{M}]$ \\
\hline malathion & $(3.7 \pm 0.2) \times 10^{-4}$ & $1.3 \times 10^{-4}$ & $2.1 \pm 0.2$ & 78.1 & $(1.6 \pm 0.1) \times 10^{-4}$ \\
malaoxon & $(2.4 \pm 0.3) \times 10^{-6}$ & $5.6 \times 10^{-6}$ & $2.1 \pm 0.2$ & $3.6 \times 10^{3}$ & $(3.4 \pm 0.1) \times 10^{-6}$ \\
isomalathion & $(3.2 \pm 0.3) \times 10^{-6}$ & $7.2 \times 10^{-6}$ & $1.9 \pm 0.3$ & $2.9 \times 10^{3}$ & $(2.7 \pm 0.2) \times 10^{-6}$ \\
diethyl maleate & $(6.0 \pm 0.5) \times 10^{-2}$ & - & - & - & $(5.5 \pm 0.1) \times 10^{-2}$ \\
O,O-dimethyl thiophosphate & - & - & - & - & - \\
[OOS(S)] & - & - & - & - & - \\
\hline
\end{tabular}

Although malathion, malaoxon and isomalathion have similar structures (malathion and isomalathion are even isomers), it is obvious that their inhibitor efficiencies are quite different. The presence of $1 \times 10^{-5} \mathrm{M}$ malaoxon in the reaction mixture completely inhibited AChE activity, and the same concentration of isomalathion inhibited up to $80 \%$, while the effect of the same concentration of malathion on enzyme activity was negligible. The half-maximal inhibition $\left(\mathrm{IC}_{50}\right.$ ) of enzyme activity was achieved at $(3.7 \pm 0.2) \times 10^{-4} \mathrm{M}$ for malathion, while the same effect was observed with concentrations of malaoxon $(2.4 \pm 0.3) \times 10^{-6} \mathrm{M}$ and isomalathion $(3.2 \pm 0.3) \times 10^{-6} \mathrm{M}$ that were two orders of magnitude lower than concentration of malathion. On the contrary, diethyl-maleate did not induce a marked reduction of enzyme activity at concentrations of up to $10 \mathrm{mM}$ (Figure 2a), while O,O-dimethyl thiophosphate and $[\mathrm{OOS}(\mathrm{S})]$ did not noticeably affect bovine erythrocyte AChE activity at all investigated concentrations $\left(1 \times 10^{-9}\right.$ to $\left.1 \times 10^{-1} \mathrm{M}\right)$.

The effects of malathion and its related compounds on the activity of immobilized AChE

The response to malathion and its related compounds of the bioanalytical FIA-system containing immobilized bovine erythrocyte $\mathrm{AChE}$ was followed with the same concentration range $\left(1 \times 10^{-9} \mathrm{M}-1 \times\right.$ $10^{-1} \mathrm{M}$ ) as was used for in vitro exposure of free AChE. The FIA-signals obtained in the absence (control activity $-a_{\mathrm{o}}$ ) and in the presence $\left(\mathrm{a}_{\mathrm{r}}\right)$ of several concentrations of malaoxon and isomalathion are presented in Figure 5. The inhibition curves describing the activity dependence of the immobilized AChE activity on the concentrations of malathion, malaoxon and isomalathion have a sigmoidal shape (Figure $2 b$ ) and are almost equal, as in the case of free AChE
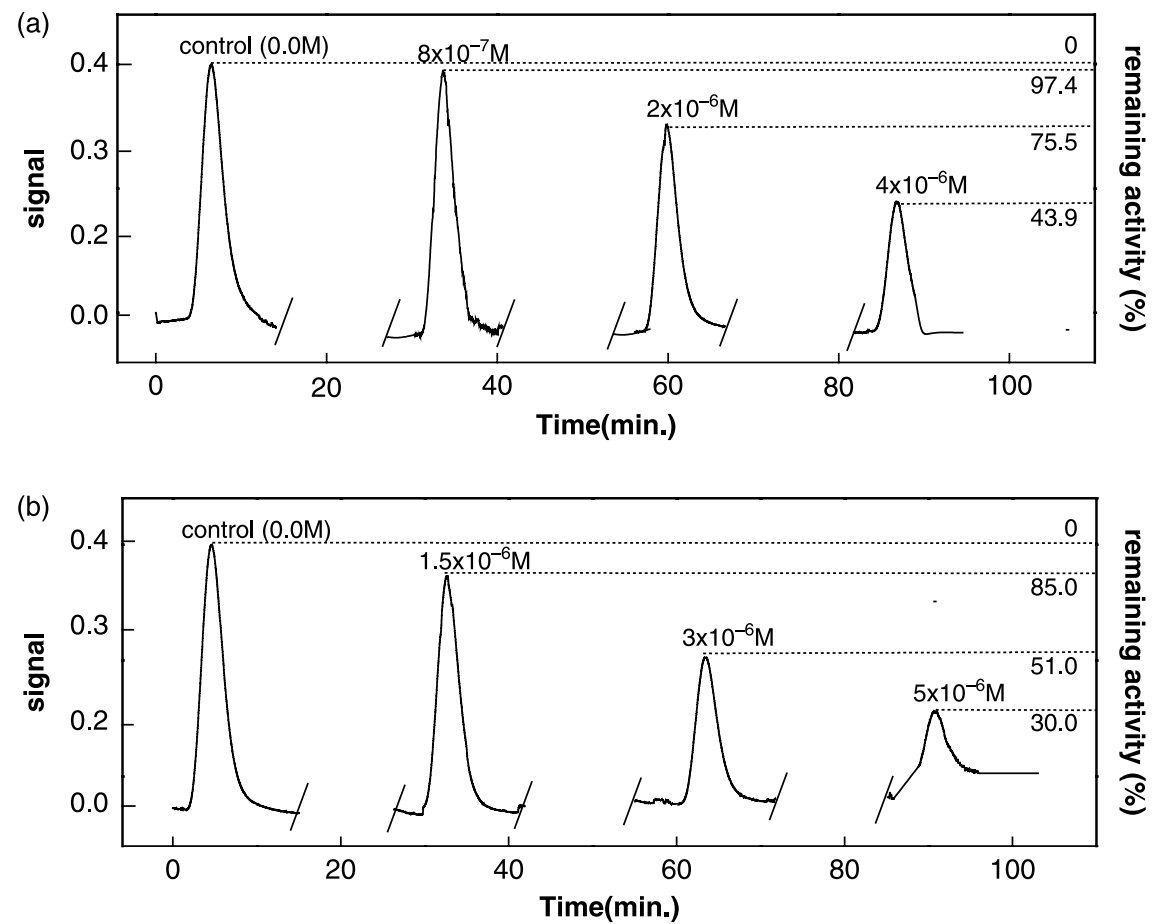

Figure 5. FIA signals obtained in the absence and presence of several concentrations of a) malaoxon and b) isomalathion. 
Table II. The limits of detection (LOD) of malathion and the products of its photodegradation by free and immobilized bovine erythrocytes AChE obtained without and after 5 min preincubation of the enzyme with selected compounds. The values of LOD were determined as the concentration that induced $10 \%$ inhibition of the control enzyme activity.

\begin{tabular}{lccr}
\hline & \multicolumn{2}{c}{ without preincubation } & after 5 min preincubation \\
\cline { 2 - 4 } compound & LOD by free AChE $(\mathrm{M})$ & LOD by immobilized AChE $(\mathrm{M})$ & LOD by free AChE $(\mathrm{M})$ \\
\hline malathion & $1.60 \times 10^{-4}$ & $0.75 \times 10^{-4}$ & $1.5 \times 10^{-5}$ \\
malaoxon & $0.77 \times 10^{-6}$ & $1.10 \times 10^{-6}$ & $1.4 \times 10^{-7}$ \\
isomalathion & $1.10 \times 10^{-6}$ & $0.93 \times 10^{-6}$ & $2.0 \times 10^{-7}$ \\
diethyl maleate & $>1 \times 10^{-2}$ & $>1 \times 10^{-2}$ & $>1 \times 10^{-2}$ \\
O,O-dimethyl thiophosphate & - & - & - \\
[OOS $(\mathrm{S})]^{\star}$ & - & - & - \\
\hline
\end{tabular}

$\star$ no noticable inhibition.

(Figure 2a). The concentrations that reduce the response by $50 \%$ ( $\mathrm{IC}_{50}$ values), obtained by fitting the experimental results with sigmoidal function, are summarized in Table I.

As can be seen from Table I, the observed differences in the responses of the enzyme to the investigated compounds are similar in both cases. The flow rate was adjusted to keep the contact time between the enzyme and pesticides below $1 \mathrm{~min}$. This ensured that the $\mathrm{IC}_{50}$ values obtained formed inhibition curves for native and immobilized enzymes can be compared. The $\mathrm{IC}_{50}$ values for immobilized enzyme for malaoxon $(3.4 \pm 0.1) \times 10^{-6}$ and isomalathion $(2.7 \pm 0.2) \times 10^{-6} \mathrm{M}$ are two orders of magnitude lower than the $\mathrm{IC}_{50}$ value of malathion $(1.6 \pm 0.1) \times 10^{-4} \mathrm{M}$. The hydrolysis product diethyl maleate did not affect the activity of the immobilized enzyme at concentrations $<10 \mathrm{mM}$, while the effects of O,O-dimethyl thiophosphate and $[\mathrm{OOS}(\mathrm{S})]$ on enzyme activity were negligible at all investigated concentrations $(<100 \mathrm{mM})$.

\section{The limits of detection (LODs) in bioassays}

The limits of detection (LODs) of malathion and its related compounds by both of the bioassays used were determined and are sumarized in Table II. The LODs of selected compounds were calculated by taking the concentrations of the investigated compounds that resulted in a $10 \%$ inhibition of the control enzyme activity under the experimental conditions described in Materials and Methods. $10 \%$ decrease of the control enzyme activity is statistically significant modification and undoubtedly indicates presence of inhibitor. It is obvious that the obtained differences in the limits of detection are in accordance with the obtained differences in inhibition power of selected compounds.

Since the results showed that the responses of the immobilized enzyme to malathion and its inhibiting byproducts are unchanged with respect to the free enzyme at incubation times below $30 \mathrm{~s}$, the effect of the time of exposure to the investigated compounds on in vitro inhibition of AChE was studied. By doing this, the sensitivity of the bioassays used towards malathion and its photoinduced by-products could be further improved, but this comes at the expense of additional analysis time.

The in vitro inhibition of AChE by malathion, malaoxon and isomalathion as a function of exposure time was followed within the time interval from 0 to 20 minutes. The standard medium assays were preincubated for different times at $37^{\circ} \mathrm{C}$ in the absence (control) and presence of the desired concentrations of the investigated OPs $\left(2 \times 10^{-4} \mathrm{M}\right.$ for malathion, $1.2 \times 10^{-6} \mathrm{M}$ for malaoxon and $1.2 \times 10^{-6} \mathrm{M}$ for isomalathion).

The inhibition of acetylcholinesterase activity by malathion, malaoxon and isomalathion increased as a function of exposure time within the interval from 0 to 5 minutes, but exposure times which were longer than 5 minutes did not induce significant increases in AChE inhibition. Moreover, the first two minutes of enzyme incubation with the inhibitors caused a rapid decrease (more than $40 \%$ ) in enzyme activity, while a gradual decrease in AChE activity was obtained during the next 3 minutes of exposure to the selected compounds in all cases (Figure 6). For example, at a concentration of $1.2 \times 10^{-6} \mathrm{M}$, malaoxon inhibited

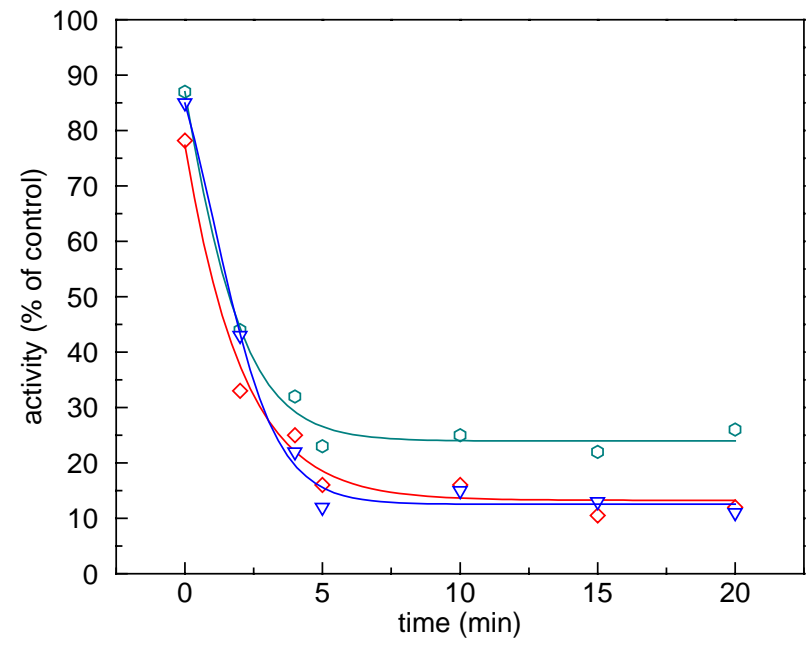

Figure 6. The dependence of the AChE activity on time of exposure to $2 \times 10^{-4} \mathrm{M}$ malathion (triangle), $1.2 \times 10^{-6} \mathrm{M}$ malaoxon (square) and $1.2 \times 10^{-6} \mathrm{M}$ isomalathion (circle). 
AChE up to $22 \%$ without incubation, $67 \%$ after 2 minutes of incubation, and $85 \%$ after 5 minutes of incubation with the enzyme. The limits of detection (LODs) of malathion, malaoxon and isomalathion by free AChE incubated with the inhibitors for 5 minutes were compared to the LODs determined from the inhibition curves obtained without incubation (Table II). As expected, a significant improvement, about one order of magnitude, was observed with 5 minute incubations of the enzyme with the inhibitors at $37^{\circ} \mathrm{C}$ before adding the normal substrate (ASChI).

\section{Inhibition of AChE activity by simultaneous exposure to malathion and its photoinduced by-products}

Different synthetic mixtures of AChE-inhibiting compounds were prepared on the basis of data obtained in our previously reported photodegradation study [8]. The expected inhibition of AChE by mixtures of these compounds is not always the sum of the individual inhibition capacities, while synergis$\mathrm{m} /$ antagonism effects are expected.

The concentrations of malathion and its by-products in the mixture were chosen using two criteria: 1 ) the concentrations of mixture components were similar to the concentrations identified by gas chromatography mass spectrometry (GC-MS) after photodegradation of $1 \times 10^{-5} \mathrm{M}$ malathion in the time interval from 0 to 60 minute [8] and 2) concentrations of the malathioninhibiting by-products, malaoxon and isomalathion, were in the concentration range around or lower than their $\mathrm{IC}_{50}$ values.

1) The inhibitions of AChE activity obtained after 5 minutes of preincubation of the enzyme with the desired combinations malathion and/or its by-products are presented in Table III and compared to the inhibitions achieved in the presence of each single compound. It is obvious that conversion of $10 \%$ of $1 \times 10^{-5} \mathrm{M}$ malathion to malaoxon caused a more than $70 \%$ AChE inhibition. The amount of malathion $\left(9 \times 10^{-6} \mathrm{M}\right)$ that remained unconverted after $10 \mathrm{~min}-$ utes of photodegradation did not affect the inhibitor capacity of malaoxon at a concentration $1 \times 10^{-6} \mathrm{M}$, since malaoxon by itself inhibited the enzyme by $71 \%$ of initial AChE activity (Table III). Combinations of malathion and its by-products formed during 1530 minutes of photodegradation completely inhibited the activity of AChE. This is reasonable, because malaoxon at a concentration of $2 \times 10^{-6} \mathrm{M}$ (by separate exposure, as well as in the presence of investigated concentrations of malathion) inhibited AChE up to $90 \%$, while the separate exposure of the enzyme to $3 \times 10^{-6} \mathrm{M}$ isomalathion induced an inhibition of $80 \%$. The presence of malathion in the combinations malathion/malaoxon or malathion/ isomalathion did not affect the inhibition caused by single exposure to malaoxon or isomalathion. Phosphorodithioic $O, O, S$ trimethyl ester did not alter inhibitor capacity in all investigated combinations with malaoxon or isomalathion.

2) Synergism/antagonism between malaoxon and isomalathion inhibition power were studied by 5 minute preincubation of the enzyme with mixtures of malaoxon and isomalathion at concentrations which, with individual exposure, produced around $50 \%$ inhibition or less. Table IV shows the means of the experimental values and the mathematical data calculated as the sum of organophosphate-induced inhibitions measured separately. Analysis of variance (One-way ANOVA) was used to compare the mathematical sum of inhibitions caused by separate exposures to malaoxon or isomalathion with inhibitions induced by exposure to both organophosphates in combination (simultaneously). When a significant $\mathrm{F}$ value $(\mathrm{P}<0.05)$ was obtained, a post-hoc Bonferoni test was used to determine the differences.

An antagonistic effect was defined as a statistically significant $(P<0.05)$ difference between inhibitions caused by simultaneous exposure and mathematically calculated means of enzyme inhibition for a pair of organophosphates where the former is lower than the latter.

As can bee seen from Table IV, with simultaneous exposure of enzyme to malaoxon and isomalathion in various concentration ratios, additive inhibition effects are observed at lower concentrations of the inhibitors, while a statistically significant antagonistic inhibition (i.e., lower than the sum of OP-induced inhibitions assayed separately) was obtained at higher concentration of the inhibitors.

\section{Discussion}

The results of our study show that malathion, its oxidation product malaoxon and its isomerisation product isomalathion inhibit free and immobilized AChE activities with varying potencies (Table I), as previously reported $[5,6,8,10,25]$. Since the inhibition powers of malathion and its inhibiting by-products were the same under the experimental conditions (within the range of experimental error) for the free and immobilized enzyme, it is obvious that immobilization of AChE on controlled pore glass did not affect its sensitivity to the investigated compounds, suggesting this may be a viable system to improve the speed of OP detection.

In previous papers [15-17], the responses of FIA systems constructed with AChE of different origins (electric eel, human erythrocytes, bovine erythrocytes, horse serum) but with the same initial activity have been investigated. The responses of these systems were dependent on the pesticide as well as on the enzyme. However, electric eel AChE is the most sensitive to most of the pesticides [15]. In the case of some pesticides, the sensitivity of bovine AChE is close to the sensitivity of electric eel AChE (paraoxon, propoxur, oxydemeton-methyl) [15], but higher 
Table III. Inhibition of AChE by single and simultaneous exposure to different combinations of malathion and/or its photoinduced by-products; The values in parenthesis represent concentration of OPs identified by GS-MS chromatography after different time of $1 \times 10^{-5} \mathrm{M}$ malathion photodegradation and used in inhibition experiments [8].

\begin{tabular}{|c|c|c|c|c|c|c|c|c|}
\hline \multirow{2}{*}{\multicolumn{2}{|c|}{ Time of irradiation (min.) [8]. }} & 0 & 10 & 15 & 20 & 30 & 45 & 60 \\
\hline & & \multicolumn{7}{|c|}{ Inhibition (\%) [Concentration of inhibitor (M)] } \\
\hline \multirow[t]{4}{*}{$\begin{array}{l}\text { Single exposure } \\
\text { [8]. }\end{array}$} & Malathion & {$\left[\begin{array}{c}0 \\
{\left[1 \times 10^{-5} \mathrm{M}\right]}\end{array}\right.$} & $0\left[9 \times 10^{-6} \mathrm{M}\right]$ & $0\left[5 \times 10^{-6} \mathrm{M}\right]$ & $0\left[2 \times 10^{-6} \mathrm{M}\right]$ & l & l & l \\
\hline & Malaoxon & l & {$\left[\begin{array}{c}71 \\
{\left[1 \times 10^{-6} \mathrm{M}\right]}\end{array}\right.$} & $\begin{array}{c}94 \\
{\left[2 \times 10^{-6} \mathrm{M}\right]}\end{array}$ & $\begin{array}{c}94 \\
{\left[2 \times 10^{-6} \mathrm{M}\right]}\end{array}$ & $\begin{array}{c}94 \\
{\left[2 \times 10^{-6} \mathrm{M}\right]}\end{array}$ & l & l \\
\hline & Isomalathion & / & / & $\begin{array}{c}80 \\
{\left[3 \times 10^{-6} \mathrm{M}\right]}\end{array}$ & $\begin{array}{c}80 \\
{\left[3 \times 10^{-6} \mathrm{M}\right]}\end{array}$ & $\begin{array}{c}80 \\
{\left[3 \times 10^{-6} \mathrm{M}\right]}\end{array}$ & $\begin{array}{c}80 \\
{\left[3 \times 10^{-6} \mathrm{M}\right]}\end{array}$ & $\begin{array}{c}67 \\
{\left[1 \times 10^{-6} \mathrm{M}\right]}\end{array}$ \\
\hline & {$[\mathrm{OOS}(\mathrm{S})]$} & l & / & 1 & $0\left[3 \times 10^{-6} \mathrm{M}\right]$ & $0\left[5 \times 10^{-6} \mathrm{M}\right]$ & $0\left[7 \times 10^{-6} \mathrm{M}\right]$ & $0\left[9 \times 10^{-6} \mathrm{M}\right]$ \\
\hline \multirow{6}{*}{$\begin{array}{l}\text { Simultaneous } \\
\text { exposure } \star \star\end{array}$} & Malathion + malaoxon & I & 74.0 & 90.4 & 92.7 & $I$ & $I$ & $I$ \\
\hline & Malathion + isomalathion & I & I & 78.6 & 76.4 & I & I & I \\
\hline & Malaoxon $+[\mathrm{OOS}(\mathrm{S})]$ & I & I & I & 93.2 & 92.1 & I & I \\
\hline & Isomalathion $+[\mathrm{OOS}(\mathrm{S})]$ & I & I & I & 80.5 & 79.3 & 82.5 & 67 \\
\hline & Malathion + malaoxon + isomalathion & I & I & 96.0 & 98.5 & / & 1 & I \\
\hline & $\begin{array}{l}\text { Malathion }+ \text { malaoxon }+ \text { isomalathion }+ \\
{[\mathrm{OOS}(\mathrm{S})]}\end{array}$ & I & I & I & 95.1 & I & I & I \\
\hline
\end{tabular}

$\star$ Data from ref. [8]

$\star \star$ Concentrations of mixture components used in simultaneous exposure experiments are the same as given in the data for single exposure after related time of irradiation. 
Table IV. Inhibition of AChE activity induced by simultaneous exposure to malaoxon and isomalathion in mixtures. Values in parenthesis represent organophosphate-induced inhibition measured separately (by single exposure).

Inhibition (\%)

\begin{tabular}{lcccc}
\hline $\begin{array}{l}\text { Isomalathion } \\
(\mathrm{M})\end{array}$ & $3 \times 10^{-7}(13.5 \%)$ & $4.5 \times 10^{-7}(35.8 \%)$ & $6 \times 10^{-7}(45.6 \%)$ \\
\hline $2 \times 10^{-7}(9 \%)$ & $2 \times 10^{-7}(10 \%)$ & $25.0 \%$ & $42.0 \%$ & $39.7 \%$ \\
$3 \times 10^{-7}(41 \%)$ & $21.3 \%$ & $40.3 \%$ & $63.1 \%$ & $51.5 \%$ \\
$4 \times 10^{-7}(57.1 \%)$ & $39.5 \%$ & $56.9 \%$ & $57.9 \%$ & $67.5 \%$ \\
\hline
\end{tabular}

LODs were achieved for different organophosphorous and carbamate pesticides with human erythrocytes AChE. The differences in the inhibition curves for different enzymes were, however, negligible if sufficient contact time between the enzyme and the pesticide was allowed by an optimal flow rate.

Several immobilization techniques would be suitable for the purpose of this work, but due to the simplicity and the availability of the materials, the enzyme was immobilized onto a solid carrier which was kept in the reactor, separate from the detector, and which could be easily removed and replaced with fresh active enzyme [15]. As a support for enzyme immobilization, controlled pore glass is the most often used material $[16,26]$. The enzyme cross-linked with glutaraldehyde [27] showed good operational and storage stability (the enzyme was stable during one day of operation and the enzyme activity remained unchanged over 6 months of storage [17]). The reproducibility of the initial enzyme activity for different bioanalytical columns prepared according to this immobilization procedure was satisfactory and did not differ by more than $6 \%$ from the initial enzyme activity. Spectrophotometric detection is simple, easy to implement and cost-effective. However, while the time of analysis required for one determination of enzyme activity is about $2 \mathrm{~min}$, the sensitivity is not very high and sometimes does not satisfy EU Framework Directive requirements [14,28]. Although most flow-through enzyme sensors for pesticide analysis are electrochemical [29], a new detection method (thermal lens spectrometry) was recently applied in combination with a cholinesterase biosensor and showed low limits of detection [15-17].

The obtained results (Figure 2 and Table I) are in accordance with previosly reported findings that malathion toxicity is increased by its break-down products $[4,5,30]$ and that most OPs need to be metabolized to their active oxons to cause potent AChE inhibition [25]. The replacement of sulphur with oxygen in the cases of both malaoxon and isomalathion causes an increased positive charge density on the central phosphorous atom, facilitating the nucleophilic attack of the $-\mathrm{OH}$ group of serine. Recently, quantitative structure-activity relationships represented an attempt to corelate the structural properties of some carbamates and isoelectronic and isostructural diaza- and dioxophospholes with AChE inhibition [31,32]. Although the investigated organophosphates have similar structures, it is clear that the combination of substituents at the central phosphorous atom is responsible for their different inhibition powers. This finding can be ascribed to the polarity of the chemical bond that binds phosphorous to sulfur (malathion, malaoxon) or oxygen (isomalathion) atoms. It seems that the strong covalent character of malathion the $\mathrm{P}-\mathrm{S}$ bond complicates the nucleofilic attack of the serine $-\mathrm{OH}$ group from $\mathrm{AChE}$. The consequence of this is a decrease in phosphorylation, i.e., a relatively high $\mathrm{IC}_{50}$ value. On the contrary, the $\mathrm{P}-\mathrm{S}$ bond in the cases of isomalathion and malaoxon are more polar, and the central phosphorous atom is more suitable for the nucleophilic attack of the serine $-\mathrm{OH}$ group from AChE. Moreover, the double-bonded oxygen atom in both cases increases the electropositivity of the central phosphorous atom, and facilitates the phosphorylation of the enzyme. The consequence of this is a higher inhibitory potency for these compounds.

Thus, the obtained $\mathrm{K}_{\mathrm{I}}$ and $\mathrm{k}_{3}$ values for malathion and its inhibiting by-products are in accordance with the allosteric effects noticed between the top and the bottom of the gorge $[22,33,34]$. The progressive development of irreversible inhibition is consistent with the hypothesis that these compounds react with the enzyme to yield a phosphorylated enzyme derivative.

However, the reaction rates for malaoxon and isomalathion are similar, and differ strongly compared to the same values for malathion. As the consequence, the ability of malaoxon and isomalathion to act as phosphorylating agents in general and the degree of molecular complementarity between the compounds and the enzymes is increased compared to malathion, their parent compound. The absence of an inhibitory effect on AChE activity for O,O-dimethyl thiophosphate is undoubtedly a consequence of the absence of a 1,2-(diethoxycarbamyl) ethyl group, which is present in the molecules of the investigated organophosphate inhibitors. Since, organophosphates are substrate analogues of acetylcholine, it seems that this group is necessary for interaction between the substrate and the anionic site of the AChE active site, which is responsible for the appropriate position- 
ing of the substrate within the enzyme active site [35] Moreover, these findings are in agreement with the inhibitory effect of diethyl-maleate obtained at concentrations $\geq 10 \mathrm{mM}$.

The absence of an inhibitory effect for $O, O, S$ trimethyl phosphorodithioate $[\mathrm{OOS}(\mathrm{S})]$ at all investigated concentrations is in agreement with previously reported findings [36]. In fact, [OOS(S)] did not affect the inhibition power of malathion inhibiting byproducts in all investigated combinations with these compounds (Table III). The compound requires metabolic activation, probably through oxidation to $O, O, S$-trimethyl phosphorothioate $[\mathrm{OOS}(\mathrm{O})]$ or isomerisation to $O, S, S$-trimethyl phosphorodithioate $[\mathrm{OSS}(\mathrm{O})]$. The toxicity of these compounds $([\mathrm{OOS}(\mathrm{O})]$ and $[\mathrm{OSS}(\mathrm{O})])$ as anticholinesterases comes from their ability to rapid age the enzyme [37]. The inhibition of enzyme activity during the $15^{\text {th }}$ to $60^{\text {th }}$ minutes of the irradiation experiment, where malathion and its by-products were simultaneously added to AChE (Table III), confirms that the inhibitory power of the malathion-irradiated samples can be attributed to the formation of malaoxon and isomalathion during malathion photodegradation.

The additive inhibition of AChE activity obtained by simultaneous exposure to low concentrations of malaoxon and isomalathion (Table IV) confirms that both inhibitors bind to the same binding site and that there is an excess of inhibitor binding sites. The antagonistic inhibition of bovine erythrocyte AChE in the presence of mixtures of inhibitors at higher concentrations can be explained by competition between inhibitors for a limited number of inhibitor binding sites on the enzyme.

The obtained dependence of AChE activity on the time of exposure to the inhibitors is in agreement with results reported earlier [15] and shows that the sensitivity of bioassay used towards the investigated compounds can be improved by increasing the contact time between the enzyme and organophosphate.

\section{Conclusions}

The sensitivity of the immobilized enzyme towards the investigated compounds is unchanged with respect to the free enzyme. Thus, the detection and determination of OPs and their mixtures, as well as the evaluation of their toxicity, can be performed using an FIA bioassay containing immobilized bovine erythrocyte AChE.

$O, O, S$-trimethyl phosphorodithioate $[\mathrm{OOS}(\mathrm{S})] \mathrm{did}$ not alter the activity of the enzyme at all investigated concentrations. Its formation in samples of irradiated malathion, however, raises concerns because of its ability to bioactivate into $O, O, S$-trimethyl phosphorothioate $[\mathrm{OOS}(\mathrm{O})]$ and/or to isomerise into $O, S, S$ trimethyl phosphorodithioate [OSS $(\mathrm{O})]$, which cause rapid aging of the enzyme and delayed toxicity through anticholinesterase activity.
The sensitivity towards malathion and its photoinduced by-products of bioassay used can be improved by increasing the incubation time of the enzyme with organophosphate, but this comes at the expense of additional analysis time.

It can be concluded that the FIA-AChE bioassay makes possible the detection and determination of OP break-down products, which are usually not target analytes in monitoring surveys, although they have been proven to be more toxic (such as in the cases of malaoxon and isomalathion) than their parent compound (malathion).

\section{Acknowledgements}

The authors gratefully acknowledge financial supports from Ministry of Science and Environmental Protection of the Republic Serbia, Project No.142051. The work was supported also by the Ministry of Higher Education, Science and Technology of the Republic Slovenia.

\section{References}

[1] Chambers WH. Organophosphorus compounds: An overview. In: Chambers JE, Levi PE, editors. Organophosphates, chemistry, fate, and effects. San Diego (etc.): Academic Press; 1992. p 3-17.

[2] O'Malley M. Clinical evaluation of pesticide exposure and poisonings. Lancet 1997;349:1161-1166.

[3] Solberg Y, Belkin M. The role of excitotoxicity in organophosphorous nerve agents central poisoning. Trends Pharmacol Sci 1997;18:183-185.

[4] Marrs TC. Organophosphate poisoning. Pharmac Ther 1993; 58:51-66.

[5] Bajgar J. Organophosphates/nerve agent poisoning: Mechanism of action, diagnosis, prophylaxis, and treatment. Adv Clin Chem 2004;38:151-216.

[6] Bajgar J. Laboratory diagnosis of organophosphates/nerve agent poisoning. Klin Biochem Metab 2005;13(34):40-47.

[7] Ray DE, Richards PG. The potential for toxic effects of chronic, low-dose exposure to organophosphates. Toxicol Lett 2001;120:343-351.

[8] Bavcon Kralj M, Černigoj U, Franko M, Trebše P. Comparison of photocatalysis and photolysis of malathion, isomalathion, malaoxon and commercial malathion-products and toxicity studies Water Res doi:10.1016/j. watres.2007. 06.0162007.

[9] Bavcon Kralj M, Franko M, Trebše P. Photodegradation of organophosphorus insecticides - Investigations of products and their toxicity using gas chromatography-mass spectrometry and AChE-thermal lens spectrometric bioassay. Chemosphere 2007;67(1):99-107.

[10] Borwn MA, Petreas MX, Okamoto HS, Mischeke T, Stephens RD. Monitoring of malathion and its impurities and environmental transformation products on surfaces and in air following an aerial application. Envir Sci Tech 1993;27: 388-397.

[11] Bavcon Kralj M, Trebše P, Franko M. Oxidation as a prestep in determination of organophosphorus compounds by the AChE-TLS bioassay. Acta Chim Slov 2006;53:43-51.

[12] Coupe RH, Blomquist JD. Water-soluble pesticides in finished water of community water supplies. Jour AWWA 2004;96(10): $56-68$. 
[13] Agricultural Chemical Usage 2005 Field Crops Summary Agricultural Statistics Board, May 2006, NASS, USDA.

[14] Official journal of the European Union, L146/19-20, 8.6.2007.

[15] Pogačnik L, Franko M. Optimisation of FIA system for detection of organophosphorous and carbamate pesticides based on cholinesterase inhibition. Talanta 2001;54:631-641.

[16] Pogacnik L, Franko M. Determination of organophosphate and carbamate pesticides in spiked samples of tap water and fruit juices by a biosensor with photothermal detection. Biosens Bioelectron 1999;14:569-578.

[17] Pogacnik L, Franko M. Detection of organophosphate and carbamate pesticides in vegetable samples by a photothermal biosensor. Biosens Bioelectron 2003;18:1-9.

[18] Musilek K, Kuca K, Jun D, Dohnal V, Dolezal M. Synthesis of a novel series of bispyridinium compounds bearing a xylene linker and evaluation of their reactivation activity against chlorpyrifos-inhibited acetylcholinesterase. J Enz Inh Med Chem 2005;20(5):409-415.

[19] Kuca K, Kassa J. A comparison of the ability of new bispyridinium oxime 1-(4-hydroxyiminomethylpyridinium)-4(4-carbamoylpyridinium)butane dibromide and currently used oximes to reactivate nerve agent-inhibited rat brain acetylcholinesterase by in vivo methods. J Enz Inh Med Chem 2003;18:529-535.

[20] Kuca K, Patocka J. Reactivation of cyclosarin-inhibited rat brain acetylcholinesterase by pyridinium-oximes. J Enz Inh Med Chem 2004;19:39-43.

[21] Ellman GL, Courtney KD, Andreas V, Featherstone RM. A new and rapid colorimetric determination of acetylcholinesterase activity. Biochem Pharm 1961;7:88-90.

[22] Kitz R, Wilson I. Esters of methanesulfonic acid as irreversible inhibitors of acetylcholinesterase. J Biol Chem 1962;237(10): 3245-3249.

[23] Barret EP, Joyner LG, Halenda PP. The determination of pore volume and area distributions in porous substances. I. computations from nitrogen isotherms. J Am Chem Soc 1951;73:373-380.

[24] Lowry O, Rosenbrough N, Farr A, Randal R. Protein measurement with the Folin phenol reagent. J Biol Chem 1951;193(1):265-275.

[25] Ward TR, Ferris DJ, Tilson HA, Mundy WR. Correlation of the anticholinesterase activity of a series of organophosphates with their ability to compete with agonist binding to muscarinic receptors. Toxicol Appl Pharmacol 1993;122: 300-307.

[26] Trojanowicz M, Szewczynska M. Biosensing in high-performance chemical separations. Trends Anal Chem 2005;24(2): 92-106.

[27] Leon-Gonzalez MF, Townshend A. Determination of organophosphorous and carbamate pesticide standards by liquid chromatography with detection by inhibition of immobilized acetylcholinesterase. J Chromatogr 1991;539:47-54.

[28] Dănet AF, Bucur B, Cheregi M-C, Badea M, Şerban S. Spectrophotometric determination of organophosphoric insecticides in a FIA system based on AChE inhibition. Anal Lett 2003;36:59-73.

[29] Prieto-Simón B, Campàs M, Andreescu S, Marty JL. Trends in flow-based biosensing systems for pesticide assessment. Sensors 2006;6:1161-1186.

[30] Brenner L, Malathion J. Pest Ref 1992;12(4):19-27.

[31] Lin G, Liu YC, Lin YF, Wu YG. Ortho effects in quantitative structure-activity relationships for acethylcholinesterase inhibition by aryl carbamates. J Enz Inh Med Chem 2004;19: 395-401.

[32] Gholivand K, Shariatinia Z, Ghadimi S, Alizadegan AM, Khajeh K, Naderi-Manesh H. Acetylcholinesterase inhibition by diaza- and dioxophosphole compounds: Synthesis and determination of IC $_{50}$ values. J Enz Inh Med Chem 2004;19: 403-407.

[33] Smulders CJGM, Bueters TJH, van Kleef RGDM, Vijverberg HPM. Selective effects of carbamate pesticides on rat neuronal nicotinic acetylcholine receptors and rat brain acetylcholinesterase. Toxicol Appl Pharmacol 2003;193:139-146.

[34] Boublik Y, Saint-Aguet P, Lougarre A, Arnaud M, Villatte F, Estrada-Mondaca S, Fournier D. Acetylcholinesterase engineering for detection of insecticide residues. Protein Eng Des Sel 2002;15:43-50

[35] Harel M, Schalk I, Ehret-Sabatier L, Bouet F, Goeldner M, Hirth C, Axelsen PH, Silman I, Sussman JL. Quaternary ligand binding to aromatic residues in the active-site gorge of acetylcholinesterase. Proc Natl Acad Sci 1993;90:9031-9035.

[36] Talcott RE, Mallipudi NM, Umetsu N, Fukuto TR. Inactivation of esterases by impurities isolated from technical malathion. Toxicol Appl Pharmacol 1979;49(1):107-112.

[37] Clothier B, Johnson MK, Reiner E. Interaction of some trialkyl phosphorothiolates with acetylcholinesterase characterization of inhibition, aging and reactivation. Biochim Biophys Acta 1981;660(2):306-316. 